ments have been made for visits to the National Physical Laboratory, the Royal Aircraft Establish. ment, the National Gas Turbine Establishment, and the Research Laboratories of the General Electric Co., Ltd., during the week following the Congress. Forms of application for membership, and other material concerning the Congress, can be obtained from the Organising Secretary, Seventh International Congress of Applied Mechanics, Imperial College of Science and Technology, London, S.W.7.

\section{Theories of Creep in Metals}

A summer school in theoretical physics, with particular application to creep in metals, will be held in the H. H. Wills Physical Laboratory of the University of Bristol during June 2-5. The course is intended mainly for members of the staffs of Government and industrial laboratories who wish to familiarize them. selves with the theoretical side of subjects with which they have been concerned on the experimental side. Lectures will be given by Prof. N. F. Mott and other members of the staff of the H. H. Wills Physical Laboratory. In addition to the regular lectures, there will be opportunities for research workers attending the course to discuss their own work and its theoretical implications. Subjects to be treated will include : anelastic effects due to slip at grain boundaries; grain growth, recrystallization and the theory of grain boundary slip; geometry of dislocation and the theory of slip bands; theory of transient creep ; slip in solid solutions ; diffusion of carbon in iron and elastic after-effect; effects of carbon on the mechanical properties of iron; mechanisms of internal damping; crystal growth and the origin of dislocations. The number attending the course will be limited to about fifty, and the fee for attendance 5 guineas. Further particulars and forms of application, to be returned by April 15, can be obtained either from the Director of the Department of Adult Education, University of Bristol, or from the Secretary of the Institute of Physics, 47 Belgrave Square, London, S.W.1.

The University of Bristol, in co-operation with the Institute of Physics, announces also a second summer school in the physies of solids (experimental and theoretical) to take place in Bristol during September 8-15, the subject being "The Oxides and Ionic Crystals". Further details will be announced in due course.

\section{University of London}

Dr. Leslie Young, reader in biochemistry in University College, London, and formerly professor of biochemistry in the University of Toronto, has been appointed to the university chair of biochemistry tenable at St. Thomas's Hospital Medical School as from April 1.

The degree of D.Sc. has been conferred on : Mr. W. S. Rogers (East Malling Research Station); Dr. B. N. Singh (Rothamsted Experimental Station); Mr. F. L. Warren (Royal Cancer Hospital (Free)).

\section{Industrial Research in Wales}

A regional conference on "Industry and Research in Wales", organised jointly by the Industrial Research Committee of the Federation of British Industries and the Industrial Association of Wales and Monmouthshire, will be held at Cardiff on March 10. Sir William Griffiths, managing director of the Mond Nickel Co., Ltd., will preside at the morning session and Sir Gerald Bruce, of the Industrial
Association of Wales and Monmouthshire, in the aftermoon. Among others taking part will be Sir Frederick Rees, principal of University College, Cardiff, Dr. W. D. Scott, of Monsanto Chemicals, Ltd., Capt. H. Leighton Davies, of the Steel Company of Wales, Ltd., Mr. Harry Davies, of I.C.I., Ltd., Dr. Idris Jones, of the National Coal Board, and Mr. R. K. Sanders, of the Metal Box Co., Ltd. Sir Percy Thomas, of the Welsh Board for Industry and the Industrial Association of Wales and Monmouthshire, will sum up. Further particulars can be obtained from the Industrial Research Secretariat, F.B.I., 21 Tothill Street, London, S.W.1, or from the Industrial Association of Wales and Monmouthshire, Aberdare House, Mountstuart Square, Cardiff.

\section{Convention on Scientific Radio}

A Convention on Scientific Radio is to be held during April 7 and 8 by the Institution of Electrical Engineers and the British National Committee for Scientific Radio (set up under the auspices of the Royal Society), and is being organised by the Radio Section of the Institution. This is intended to serve as a preliminary survey of the British contribution in the radio field which is to be presented at the forthcoming meeting of the Union Radio Scientifique Inter. nationale to be held in August 1948 in Stockholm. The Convention is divided into four sessions, corresponding in scope to those of the International Union, covering (1) standards and measurements; (2) propagation; (3) radio noise; and (4) radio physics.

\section{Announcements}

General Smuts has been elected chancellor of the University of Cambridge in succession to the late Lord Baldwin.

Dr. Harold Scarborough has been appointed lecturer with title of reader in the Department of Medicine, University of Birmingham.

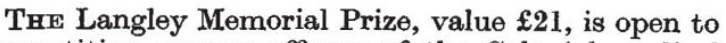
competition among officers of the Colonial medical service who are serving, or who have served, in West Africa. The prize will be awarded for the best paper submitted on a topic falling within one of the follow. ing subjects (special consideration being given to original work): (a) tropical medicine or surgery; (b) tropical hygiene and sanitation; (c) tropical entomology and parasitology. Papers, which may consist of either published or unpublished work, should be delivered to the Assistant Dean, London School of Hygiene and Tropical Medicine, Keppel Street, Gower Street, London, W.C.1, not later than October 1, 1948.

THE trustees of the Lady Tata Memorial Fund invite applications for grants and scholarships, open to workers of any nationality, for research in diseases of the blood, with special reference to leukæmia, in the academic year beginning on October I, 1948. Grants are made for research expenses or to provide scientific assistants to senior workers; scholarships ( $£ 400$ per annum for whole-time research) are awarded as personal remuneration. Forms of application, to be returned before March 31 , can be obtained by writing to the secretary of the Scientific Advisory Committee, Lady Tata Memorial Trust, c/o Medical Research Council, 38 Old Queen Street, Westminster, London, S.W.1. 